\title{
SÜRDÜRÜLEBİLİRLİK RAPORLAMASI VE XBRL *
}

\section{Öğr. Gör. Dr. Filiz YÜKSEL ${ }^{\mathrm{a}}$ Prof. Dr. Cevdet KAYALI ${ }^{b}$ Doç. Dr. Nilgün KAYALI ${ }^{\mathrm{C}}$}

Ampirik Araştırma

(Empirical Research)
Muhasebe ve Vergi

Uygulamaları Dergisi

Nisan 2018; Özel Sayl: 110-131

ÖZ

Sürdürülebilirlik raporu belli bir dönemde işletme faaliyetleri ile çevre, toplum ve ekonomik durum üzerinde yaratılan etkinin bilgi kullanıcılarına aktarılması için kullanılan kurumsal raporlama aracıdır. Sürdürülebilirlik raporunun hazırlanmasında ve sunulmasında Global Raporlama Girişimi (Global Reporting Initiative - GRI) tarafından yayınlanan GRI Sürdürülebilirlik Kılavuzlarında açıklanan ilkelere uyulması önerilir. İşletmeler gönüllülük esasına dayalı olarak sürdürülebilirlik raporlarını hazırlamakta ve internet sitelerinde taşınabilir belge biçimi (Portable Document Format - PDF) formatında yayınlamaktadırlar. Ancak son zamanlarda sürdürülebilirlik raporlarının Genişletilebilir İşletme Raporlama Dili (eXtensible Business Reporting Language - XBRL) ile de hazırlanması ve yayınlanması konusu çeşitli taraflarca üzerinde çalışılan bir konudur. Bu çalışmada, sürdürülebilirlik raporlaması, XBRL ve GRI XBRL Taksonomisi hakkında bilgi verilmeye çalışılacaktır.

Anahtar Sözcükler: Sürdürülebilirlik Raporlaması, Sürdürülebilirlik Raporu, XBRL, GRI XBRL Taksonomisi

JEL Kodları: M41, M49, Q56

\section{SUSTAINABILITY REPORTING AND XBRL}

\section{ABSTRACT}

Sustainability report is an corporate reporting tool that is used to provide environmental, social and economic impacts of business activities to information users in a particular period. It is recommended that the principles outlined in the GRI Sustainability Guidelines issued by the Global Reporting Initiative (GRI) to be followed in the preparation and presentation of the sustainability report. Businesses are preparing

\footnotetext{
* Bu makale, 13-17 Aralı 2017 tarihinde Erzurum'da düzenlenen 4.Uluslararası Muhasebe ve Finans Araştırmaları Kongresinde sunulmuş olan özet bildirinin genişletilmiş tam metnidir.

a Sorumlu Yazar, Dumlupınar Üniversitesi, Domaniç Hayme Ana MYO, filizyuksel@windowslive.com

b İzmir Demokrasi Üniversitesi, İ.İ.B.F. , cakayali@hotmail.com

c Manisa Celal Bayar Üniversitesi. İ.İ.B.F., nilgunkayali2002@yahoo.com
} 
sustainability reports on a voluntary basis and are publishing their reports in Portable Document Format (PDF) on their internet sites. However, the issue of preparing and publishing sustainability reports with the eXtensible Business Reporting Language (XBRL) has been a subject of interest recently. In this study, we will try to provide information about sustainability reporting, XBRL and GRI XBRL Taxonomy.

Keywords: Sustainability Report, Sustainability Report, XBRL, GRI Taxonomy

JEL Codes: M41, M49, Q56

\section{GİRİ̧}

İşletme, insan istek ve ihtiyaçlarını gidererek kazanç elde etmek amacıyla mal veya hizmet üretmek veya satmak için kurulmuş ekonomik birimdir. $\mathrm{Bu}$ bakımdan işletmeler faaliyetleri ile çevre, toplum ve ekonomi üzerinde olumlu etkiler yaratmak üzere faaliyette bulunmaktadırlar. Ancak işletme faaliyetleri ile bir yandan çevresel, toplumsal ve ekonomik açıdan olumlu etkiler yaratılırken, diğer yandan işletme faaliyetlerinin çevresel, toplumsal ve ekonomik açıdan olumsuz etkileri olabilmektedir. İşletme faaliyetlerinin çevresel, toplumsal ve ekonomik açıdan olumsuz etkileri 1970'li y1llardan itibaren başta Birleşmiş Milletler (BM) olmak üzere birçok ulusal ve uluslararası organizasyonun, ülkelerin, kurumların, kuruluşların gündeminde olan bir konudur. BM tarafından yapılan çalışmalar sonrasında Dünya Çevre ve Kalkınma Komisyonu kurulmuştur.

Dünya Çevre ve Kalkınma Komisyonu (World Commission on Environment and Development), 1983 yılının sonbaharında Birleşmiş Milletler'in 38.Oturumu'nda kabul edilen Genel Kurul Karar1 sonucu kurulmuş (www.un-documents.net) ve 1984 yilında BM Genel Kurulu tarafindan bağımsız bir organ olarak ilan edilmiştir (www.uncsd2012.org/history.html).

Dünya Çevre ve Kalkınma Komisyonu 20 Mart 1987 tarihinde "Report of the World Commission on Environment and Development: Our Common Future" başlıklı raporu yayınlamıştır. Gro Harlem Brundtland başkanlığında hazırlandığı ve yayınlandığı için Brundtland Raporu olarak da anılan bu rapor ile birlikte sürdürülebilir kalkınma kavramı literatüre girmiştir.

Sürdürülebilirlik kavramı ' genellikle BM 1987' deki raporunda verilen sürdürülebilirlik kalkınma tanımına dayanmaktadır (Roth, 2014: s.63). Sürdürülebilir kalkınma (Sustainable Development), "insanlığın gelecek 
kuşakların ihtiyaçlarını karşılama yeteneklerini tehlikeye atmaksızın bugünkü ihtiyaçlarını karşılama yetenekleridir (UN-WCED, 1987: Madde 27). Sürdürülebilir kalkınma gereği işletmeler çevresel ve toplumsal kaynakları en etkin ve verimli bir şekilde kullanarak faaliyetlerini yürütmeli ve insanların ihtiyaçlarını karşılamalıdır. Bu doğrultuda işletmeler faaliyetleri ile çevre, toplum ve ekonomi üzerindeki olumlu etkilerini arttırmaya, olumsuz etkilerini de azaltmaya çalışmaktadır. Ayrıca bu etkileri gönüllülük esasına dayalı olarak hazırladıkları sürdürülebilirlik raporları ile bilgi kullanıcılarına aktarmaktadırlar. Yaşanan teknolojik gelişmeler ile birlikte son yıllarda sürdürülebilirlik raporlarının XBRL ile hazırlanması ve yayınlanması gündeme gelmiştir. $\mathrm{Bu}$ nedenle bu çalışmada sürdürülebilirlik raporlamas1, XBRL, GRI XBRL Taksonomisi hakkında bilgi verilmeye çalışlacaktır.

\section{SÜRDÜRÜLEBILIIRLIIK RAPORLAMASI}

Sürdürülebilirlik kavramı işletme faaliyetlerinin sürdürülebilir kalkınma temelinde yürütülmesi olarak tanımlanabilir. Sürdürülebilir kalkınma temelinde planlanan ve yürütülen işletme faaliyetleri sonucunda çevre, toplum ve ekonomi üzerinde yaratılan etkinin raporlanmasında kullanılan kurumsal raporlama aracı sürdürülebilirlik raporudur.

Sürdürülebilirlik raporu bir kuruluşun çevre, toplum ve ekonomi üzerindeki (olumlu veya olumsuz) etkilerine ilişkin bildirimler iletmektedir. Böylelikle sürdürülebilirlik raporlaması, soyut konuları elle tutulabilir ve somut hale getirerek sürdürülebilirlik gelişimlerinin kuruluşun faaliyetleri ve stratejisi üzerindeki etkilerinin anlaşılmasına ve yönetilmesine yardımcı olmaktadır (GRI, 2013: s.3).

Sürdürülebilirlik raporu günlük faaliyetlerden kaynaklanan ekonomik, çevresel ve sosyal etkileri konusunda bir şirket ve ya organizasyon tarafından yayınlanan rapordur. Sürdürülebilirlik raporu aynı zamanda organizasyonun değerlerini ve yönetişim modelini sunar, stratejisi ve sürdürülebilir global ekonomiye bağlılığı arasındaki bağlantıyı gösterir (https://www.globalreporting.org/information/sustainabilityreporting/Pages/default.aspx).

112 Muhasebe ve Vergi Uygulamaları Dergisi 
GRI'ye göre sürdürülebilirlik raporlamasının amaçları şunlardır:

- Sürdürülebilirlik performansının yasalar, kurallar, yönetmelikler, performans standartları ve gönüllü girişimlerle kıyaslanması ve değerlendirilmesi,

- Kurumun sürdürülebilir kalkınma hakkındaki beklentileri nasıl etkilediğinin ve onlardan nasıl etkilendiğinin gösterilmesi ve

- Performansın, kurum içinde ve farklı kurumlarla zaman içinde karşılaştırılması (GRI, 2000-2006: s.3).

Her ne kadar gönüllülük esasına dayalı olarak hazırlansa da sürdürülebilirlik raporlaması ile belirtilen amaçlara ulaşmak, işletmenin zaman içinde sürdürülebilir kalkınmaya katkısına ilişkin bir değerlendirme yapabilmek için sürdürülebilirlik raporlarının belirli standartlar doğrultusunda hazırlanması gerekmektedir. Sürdürülebilirlik raporlamasına ilişkin standart hazırlayan ve yayınlayan kuruluş GRI'dir. GRI ilk olarak 2000 yılında yayınladığı sürdürülebilirlik raporlaması kılavuzunda zaman içinde güncellemeler yapmış ve Mayıs 2013'te GRI G4 Sürdürülebilirlik Raporlaması Kılavuzlarını yayınlamıştır. Sürdürülebilirlik raporu hazırlamada işletmelere yol gösterici nitelikte olan bu kılavuzlar "Raporlama İlkeleri ve Standart Bildirimler" ve "Uygulama El Kitabı" olmak üzere iki kılavuzdan oluşmaktadır. GRI G4 Sürdürülebilirlik Raporlaması Kılavuzları "Raporlama İlkeleri ve Standart Bildirimler" başlıklı kılavuzda işletmelerin 31 Aralık 2015 tarihinde sona eren dönemden itibaren GRI G4 Sürdürülebilirlik Raporlaması Kılavuzları'na göre sürdürülebilirlik raporlarını hazırlamalarını önermiștir.

GRI G4 Sürdürülebilirlik Raporlaması K1lavuzları "Raporlama İlkeleri ve Standart Bildirimler" başlıklı kılavuzda açıklanan raporlama ilkeleri şu başlıklardan oluşmaktadır (GRI, 2013: s.3):

Rapor içeriğinin belirlenmesine ilişkin ilkeler

- Paydaş kapsayıcılığ

- Sürdürülebilirlik kapsamı

- Önemlilik

- Tamlik 
Rapor niteliğinin belirlenmesine ilişkin ilkeler

- Denge

- Karşılaştırılabilirlik

- Doğruluk

- Zamanlilik

- Açıklık

- Güvenilirlik

GRI G4 Sürdürülebilirlik Raporlaması Kılavuzları "Raporlama İlkeleri ve Standart Bildirimler" başlıklı kılavuzda açıklanan standart bildirimler ise Genel Standart Bildirimler ve Özel Standart Bildirimlerden oluşmaktadır. Genel standart bildirimler sürdürülebilirlik raporunda bulunması gerekli görülen bilgiler olup işletme stratejisi, profili, yönetimine ve sürdürülebilirlik raporuna ilişkin bilgilerden oluşmaktadır. Özel standart bildirimler kapsamında ise işletme faaliyetlerinin çevresel, sosyal ve ekonomik etkilerine ilişkin bildirim kategorileri yer almaktadır.

\section{XBRL}

İnternet ve bilgi teknolojilerindeki gelişmeler muhasebe kayıt ve raporlamalarının elektronik ortamlarda kısa sürede gerçek zamanlı yapılmasını sağlamıştır. Yaşanan bu gelişme ile birlikte, işletmeler tarafından önceden basılı bir şekilde hazırlanan ve sunulan kurumsal raporlar, günümüzde artık taşınabilir belge biçimi (Portable Document Format - PDF) formatında veya hiper metin biçimlendirmesi dili (Hyper Text Mark-Up Language) kullanılarak internet ortamında bilgi kullanıcılarına sunulmaktadır. Diğer bir ifadeyle işletmeler tarafından dijital raporlama yapılmaktadır. Bilgi kullanıcıları internet ortamında PDF veya HTML formatında sunulan bu raporlardan istedikleri bilgileri elde edebilmektedirler. Ancak son zamanlarda, mali tabloların kolaylıkla hazırlanabilmesi, finansal kurumlar, yatırımcılar, denetçiler, devlet ve diğer analistlerin analizlerini kolaylıkla yapabilmesine imkan sağlayacak, yetkilendirilmiş kişilerce veri girişinin yapılabileceği bir raporlama diline ihtiyaç olduğu tartışılan bir konu haline gelmiştir.

$114 \quad$ Muhasebe ve Vergi Uygulamaları Dergisi 


\subsection{XBRL Kavramı ve Özellikleri}

Son 20 yılda, internetin yaygınlaşmasıyla desteklenen teknolojik bir ani değişiklik meydana gelmiştir (Beerbaum, 2015: s.36). Son zamanlarda bilgi teknolojileri ve internetin tüm işletme işlevlerine entegre edilmesiyle birlikte muhasebenin çıtısı niteliğinde olan kurumsal raporlamada XBRL konusu gündeme gelmiştir.

XBRL girişimi AICPA (the American Institute of Certified Public Accountants) tarafından etkilenerek 1998 yılında başlatılmıştır. Bu proje sonucunda, XBRL.org oluşturulmuş, ve daha sonra XBRL standartlarını destekleyen ve yasal açıdan kazanç amacı gütmeyen XBRL International adlı bağımsız bir kuruluş haline gelmiştir (Beerbaum, 2015: s.36). Kernan (2009)'a göre, World Wide Web Consortium (W3C) 1998 yılında XML (eXtensible Markup Language) için rehber yayınlamış ve XML'yi tanıtmıştır. Bu gelişme üzerine aynı yıl Charles Hoffman, bilgisayar uygulamaları arasında finansal bilgilerin paylaşılmasına, kullanılmasına imkan sağlayacak bir biçimlendirme dili için çalışmalara başlamıştır. Yaptığı çalışmalar sonucunda AICPA tarafından pazara yönelik, XML tabanlı finansal tabloların hazırlanabilmesini sağlayacak bir iş planı istenmiştir. Bu iş planında projenin adı genişletilebilir finansal raporlama biçimlendirme dili (Extensible Financial Reporting Markup Language-XFRML) olarak belirlenmiştir. İlk çalışmalar kapsamında proje ekibinde çalışan Bob Elliott büyük düşünülmesi gerektiğini, sadece finansal tablolar için değil aynı zamanda tüm iş raporlarını kapsayacak bir biçimlendirme dili üzerinde çalışmaları gerektiğini ifade etmiştir. Ayrıca pazara yönelik olarak hazırlanması istenen XFRML'nin telaffuzu konusunda da olumsuz görüşler belirtilmiştir. 1999 yılında yapılan ilk XFRML toplantısında XFRML Komitesi kurulmuş olup, "AICPA, Arthur Andersen, Cohen Computer Consulting, Deloitte\&Touche, econtent Company, Ernst\&Young, FreeEDGAR.com (şuan EDGAR Online), FRx Software Corporation, Great Plains, Microsoft, PwC, KPMG ve Woodburn Group" (Kernan, 2009: s.14) bu komitede ve toplantıda yer almışlardır. 2000 yılında yapılan toplantı sonrasında XFRML yerine XBRL ifadesinin kullanılması kararı alınmıştır.

XBRL, internet ortamında raporlama yapmaya yarayan biçimlendirme ve raporlama dilidir. "XBRL, kar amacı gütmeyen bir konsorsiyum olan XBRL International tarafından yönetilen, dijital işletme raporlaması için açık uluslararası standarttır" (https://www.xbrl.org/the-standard/what/anintroduction-to-xbrl/). XBRL, verilerin kolayca depolanması, analiz 
edilmesi ve transfer edilmesini sağlayan açık kaynaklı bir işaretleme dilidir (Coşkun, 2011: s.13). XBRL (eXtensible Business Reporting Language) finansal raporlamayı standartlaştırmak ve işletmeler, yatırımcılar, düzenleyiciler ve muhasebe uzmanlarının yer aldığ raporlama tedarik zincirinde finansal verilerin değişimini kolaylaştırmak için uluslararası topluluk tarafından geliştirilmiştir (Roohani, 2013: s.5).

XBRL, raporlama terimlerinin yetkili olarak tanımlanabileceği bir dil sunar. $\mathrm{Bu}$ ifadeler daha sonra finansal tabloların içeriğini veya diğer uygunluk türlerini, performans ve işletme raporlarını benzersiz bir şekilde temsil etmek için kullanılabilir. XBRL, raporlama bilgilerinin kuruluşlar arasında hızlı, doğru ve dijital olarak hareket etmesini sağlar (https://www.xbrl.org/the-standard/what/an-introduction-to-xbrl//).

XBRL (Extensible Business Reporting Language-Genişleyebilir İşletme Raporlama Dili) finansal bilgilerin hazırlanması, yayınlanmasi ve denetlenmesini kolaylaştıran ticari işlemlerin raporlanması için standart hale getirilmiş bir elektronik dildir (Bayazıtl1, 2002: s.119). XBRL, finansal verilerin işlenerek bilgi haline getirildiği sürecin her aşamasında veriyi yeniden işlenmeye hazır bir yapıda tutmaktadır. XBRL'nin görevi finansal bilgilerin raporlanarak bankalara, denetleyici ve düzenleyici kurumlara ve diğer bilgi kullanıcılarına ulaştırılmasına kadar da devam etmektedir. Bu yönüyle bakıldığında XBRL, işletmeye ilişkin finansal ve finansal olmayan her tür bilginin analizi ve bilgi kullanıcıları arasında değişimini güvenilir ve kolay kılacak ortamı sağlamak işlevini yerine getirmektedir.(Sevim ve Temizel, 2009: s.264).

\subsection{XBRL Kullanım Amaçları ve Faydaları}

XBRL, taksonomi adı verilen ve yetkili otoritelerce hazırlanmış standart ifadeler ile raporlama içeriğiyle sınırlandırılmış iş kurallarının oluşturularak pek çok farklı dilde ve farklı para birimiyle raporlama yapmaya imkan veren raporlama dilidir. "XBRL'nin en önemli özellikleri açık tanımlar, test edilebilir iş kuralları, çok dilli destek, güçlü yazılım desteğidir (https://www.xbrl.org/the-standard/what/anintroduction-to-xbrl/ ). Finansal bilgiler XBRL ile bir kez girilir ve işletmenin finansal tabloları, işletmenin web sitesi için HTML ve düzenleyici kurumlar için hazırlanan bir format haline getirilebilir. XBRL, internetin de dahil olduğu tüm teknoloji, birimler için finansal bilginin etkin ve yeterli hazırlanmasını, otomatik olarak değişimini ve 
güvenilir olarak açıklanmasını sağlar. XBRL tekrarlanma olasılığı olan finansal raporlama sürecini azaltacaktır ve gerçek zamanlı muhasebe sistemi için zemin hazırlayacaktır (Bayazıtl1, 2002: s.119).

Genellikle "raporlama için barkodlar" olarak adlandırılan (https://www.xbrl.org/the-standard/what/an-introduction-to-xbrl/ ) XBRL düzenleyiciler, işletmeler, hükümetler, veri sağlayıcıları, analistler ve yatırımcılar, muhasebeciler tarafından şu amaçlarla kullanılmaktadır:

- Muhasebeciler: finansal raporlarında kullanmak üzere dahili verileri konsolide etmek ve incelemek

- Denetçiler: finansal kayıtların etkili bir şekilde incelenebilmesi için

- CEO'lar ve CFO'lar: yatırımcılar ve analistlerin analitik araçlarına gerekli bilgileri yerleştirmede şeffaflık ve kontrol için bir araç olarak

- Yatırımcılar: güvenle yatırım yapmak için

- Finansal danışmanlar: işletmeler ve diğer sektörlerdeki finansal koşulları daha iyi analiz etmek ve anlamak için

- Düzenleyiciler: rapor edilen verilerin hızlı bir şekilde alınması ve analizi için (Francis, 2012: s.38).

XBRL International'a göre ise kullanım amaçları şunlardır:

- İnsanlar, içerdikleri bilgilerin doğru bir şekilde tüketilebilmesi ve analiz edilebileceği konusunda güvenle raporlar yayınlar,

- İnsanlar kaynaklarındaki hataları yakalamak ve hataları önlemek için bir dizi iş ve mantık kurallarına karşı test etmek için raporları kullanır,

- Insanlar farklı dilde, alternatif para birimleri kullanacak ve tercih ettikleri stilde dahil olmak üzere bilgileri kendi ihtiyaçlarına en uygun şekilde kullanabilirler.

- İnsanlar bu bilgileri kendilerine önceden verilmiş karmaşık tanımlamalar seti ile uyumlu olduğundan emin olmak için kullanırlar (https://www.xbrl.org/the-standard/what/anintroduction-to-xbrl/ ) 
Düzenleyiciler, işletmeler, hükümetler, veri sağlayıcıları, analistler ve yatırımcılar, muhasebeciler tarafından kullanılabilen XBRL'nin taraflara sağladığı birtakım faydalar mevcuttur. XBRL'nin ilgili taraflara sağladığı faydalar şunlardır (Uyar ve Çelik, 2006: s.100):

- İlgili kurumlara verilecek ve kamuya açıklanacak mali tablolar kolayca oluşturulabilir, ayrica bu tablolar belli standartlar ile tanımlandığından kabul edilmeme riski yaşanmayacaktır.

- Muhasebeciler; muhasebenin kayıt ve raporlama işlemlerini bu sisteme devrettiklerinden asıl işlevleri olan analiz ve yorumlama görevine odaklanabilirler.

- Banka, derecelendirme kuruluşları ve diğer ilgili kurumlar daha doğru ve daha hızlı kararlar alabilir. Bunun yanında işlem maliyetleri azalır.

- Denetçiler, analistler ve yatırımcılar; finansal bilgilerin daha hızlı gelmesi, analizlerin kolaylaşması ve konsolide bilgilere ulaşma zorluğunun azalması gibi avantajlardan faydalanırlar.

- Denetim sürecinde denetlenen işletmeden veri elde etme işleri azalır. Bu bağlamda işletme hakkında daha güvenilir bilgiler sağlanabilir ve denetim kolaylaşır.

- XBRL kullanımı, elle veri girişini asgariye indirdiği için güvenilirliği çok yüksektir, veri transferini otomatik hale getirdiğinden, operasyonel maliyetleri azaltmaktadır. XBRL verisi, çok hızlı işlenebildiği için, ticari karar süreçlerini kisaltmaktadir.

- XBRL, finansal verinin raporlanmasını ve yayımlanmasını kolaylaştırmaktadır. Finansal verilerin, üst kurumlar ve gözetim şirketlerince kolaylıkla konsolide ve karşılaştırmalı olarak analiz edilmesine olanak tanır.

- Entegrasyon maliyetleri çok düşük; uyum süresi çok kısa ve risksizdir. 


\subsection{XBRL'nin İşleyişi ve Mevcut Durumu}

XBRL standard1, XML (Extensible Markup Language, Genişletilebilir İşaretleme Dili) standardı üzerine kurulmuştur. XML temel olarak özelleştirilebilir imler (tags) kullanan ve bu etiketler sayesinde değiştokuş edilebilir, doğrulanabilir, sorgulanıp yorumlanabilir semantik veri sunuşuna olanak tanıyan bir ağ teknolojisidir. XBRL bu anlamsal içerik avantajlarını ticari ve finansal gereksinmeler doğrultusunda özelleştirerek, iş dünyasına veri akışını rahatlatan bir açılım sunmaktadır. (Coşkun, 2011: s.13)

Finansal bilgileri standart bir internet sayfasında veya basılı bir belgede olduğu gibi metin bloğu olarak ele almak yerine, XBRL statik verileri "etkileşimli" ve "akılllı" hale getirir. Her bir iş bilgisi verilerin çeşitli veri kullanıcılarına ve diğer bilgisayarlardan ulaşılarak sunumu, analizi ve depolanması için ulaşılabilir hale getirerek kendi etrafında ayrıntılı açıklayıcı ve içerik bilgisine sahiptir (Francis, 2012: s.36).

Sanıldığının aksine, XBRL yeni muhasebe ya da istatistik standartları belirlememektedir. Tersine, mevcut standartların belirli özelliklerini, bireylerin anlayabileceği ve bilgisayarların işleyebileceği biçimde organize ederek ve elektronik olarak sunmaktadır. Diğer bir deyişle, XBRL finansal muhasebe ve raporlama süreçleriyle ilgili kavramları yeniden tanımlamak yerine mevcut kavramları elektronik ortama taşımaktadır. XBRL'nin temel işlevi finansal tabloların raporlanma sürecini geliştirmektir (Tokel, Yücel ve Öksüz, 2007: s.12). XBRL, mevcut raporlama standartları ve kavramlarını yeniden tanımlayıp sınıflandırıp, biçim şablonları ile elektronik ortama taşınması için kullanılan raporlama dilidir.

XBRL farklı bileşen ve dokümanlar içeren kompleks bir yapıya sahiptir. XBRL'nin raporlama işlemlerinde kullanımının anlaşılabilmesi için gereken en önemli dokümanlar aşağıdaki gibidir:

- XBRL spesifikasyonları,

- XBRL sinıflandirma sistemleri (taksonomileri),

- XBRL örnek belgeleri

- Stil Şablonları (Style Sheets) (Moore, 2002: s.2). 
Spesifikasyon, XBRL uyumlu dosyaların oluşturulmasını düzenleyen kurallardır (Tokel, Yücel ve Öksüz, 2007: s.14). Teknik olarak spesifikasyon, finansal terimlerin XBRL dilinde nasıl tanımlandığını anlatan bir dökümandır (Karasioğlu ve Eryiğit, 2005: s.136).

Bir taksonomi, her bir kavramın tanımlandığ 1 (bir sözlüğe benzer şekilde) finansal kavramların (unsurlar olarak bilinen) gruplandırılmasıdır. Buna ek olarak, taksonomi aynı zamanda grup içindeki kavramlar arasındaki ilişkileri tanımlar. Dolayısıyla, nakit gibi bir bilanço kalemi ile çalışıyorsanız, taksonomi nakit tanımını içerecek ve aynı zamanda nakidin cari varlıklar ve sonuçta toplam varlıklar gibi diğer bilanço kalemleriyle (taksonomi dahilinde) nasıl bir ilişkisi olduğunu gösterecektir. $\mathrm{Bu}$ üç kalem (nakit, cari varlıklar, toplam varlıklar) taksonomide bir unsur olarak tanımlanan ve sunulan finansal kavramlardir (http://www.aicpa.org/ ). Taksonomi, kavramlar arasındaki ilişkileri tanım, hesaplama ve sunum bileşenleri cinsinden, kaynaklar arasındaki ilişkileri ise referans ve etiketler cinsinden ifade eder (Tokel, Yücel ve Öksüz, 2007: s.14).

Örnek belge, işletmenin belirli raporlama bilgilerini bilgisayarların akıllıca tanıyabileceği ve değiştirebileceği bir yapıda sunan dosyadır. Örnek belge her şeyin bir araya geldiği bir XML dosyasıdır. Burada varlığa özgü veri bağlantıları (etiketler), çok sayıda kullanıcının kullanımı için otomatik olarak doğrulanabilir ve iletilebilir XBRL belgesini oluşturmak için sınıflandırmalardaki ögelere yönlendirilir (http://www.aicpa.org/interestareas/).

Stil şemaları, bir web sayfası içerisindeki kodların web tarayıcısına nasıl ekrana yansitılması gerektiğini söyleyen en önemli ögedir (https://wmaraci.com/nedir/stylesheet ). XBRL okunabilir raporlar üreten örnek dokümanlar, açıklayıcı etiketler ve verilen toplamıdır. Eğer şirket baskılı finansal raporlar hazırlamak isterse örnek doküman yeterli olmayacaktır. Çünkü örnek doküman finansal rapor gibi görünmemektedir. XBRL görüneni elde etmek için tasarlanmamıştır. XBRL verilerin güvenli ve birbirini tutan şekilde sistemler arasında taşınabilmesi için tasarlanmıştır. Finansal raporlar gibi raporlar, CSS (Cascading Style Sheets), XSL (Extensible Stylesheet Language) gibi stil şablonları veya diğer teknolojilerin kullanımı ile meydana getirilir (Karasioğlu ve Eryiğit, 2015:138). Stil şablonları, XBRL'den elde edilen bilgileri önceden oluşturulmuş formattaki raporlara dönüştüren bir araç işlevi görmektedir (Acar ve Öksüz, 2013: s.70). 
İşletme faaliyetleri ile ilgili bilgiler bir veri tabanında toplanıp taksonomiler vasıtasıyla XBRL ile raporlama yapılabilir veya bir bilişim, yazılım şirketinden yardım alınarak var olan programlara bir ara yüz eklenmesi ile XBRL ile raporlama yapılabilir. Şekil-1'de de görüldügü gibi, öncelikle raporlama standartlarına uygun spefikasyonlar geliştirilir. Her bir raporlama kalemi için taksonomi olarak adlandırılan etiketler veya sınıflandırma sistemleri geliştirilir. Bu taksonomiler doğrultusunda Notepad gibi basit bir bilgisayar programı vasıtasıyla bile veya diğer bilgisayar yazılımlarıyla örnek doküman oluşturulur. Hazırlanan örnek doküman XML dosyası şeklinde kaydedilerek aracı veya düzenleyici kurumun kontrolündeki XBRL deposuna aktarılır. Bilgi kullanıcısı veri deposundaki bu raporlara ulaşarak istediği işlemi veya değişikliği yapabilir.

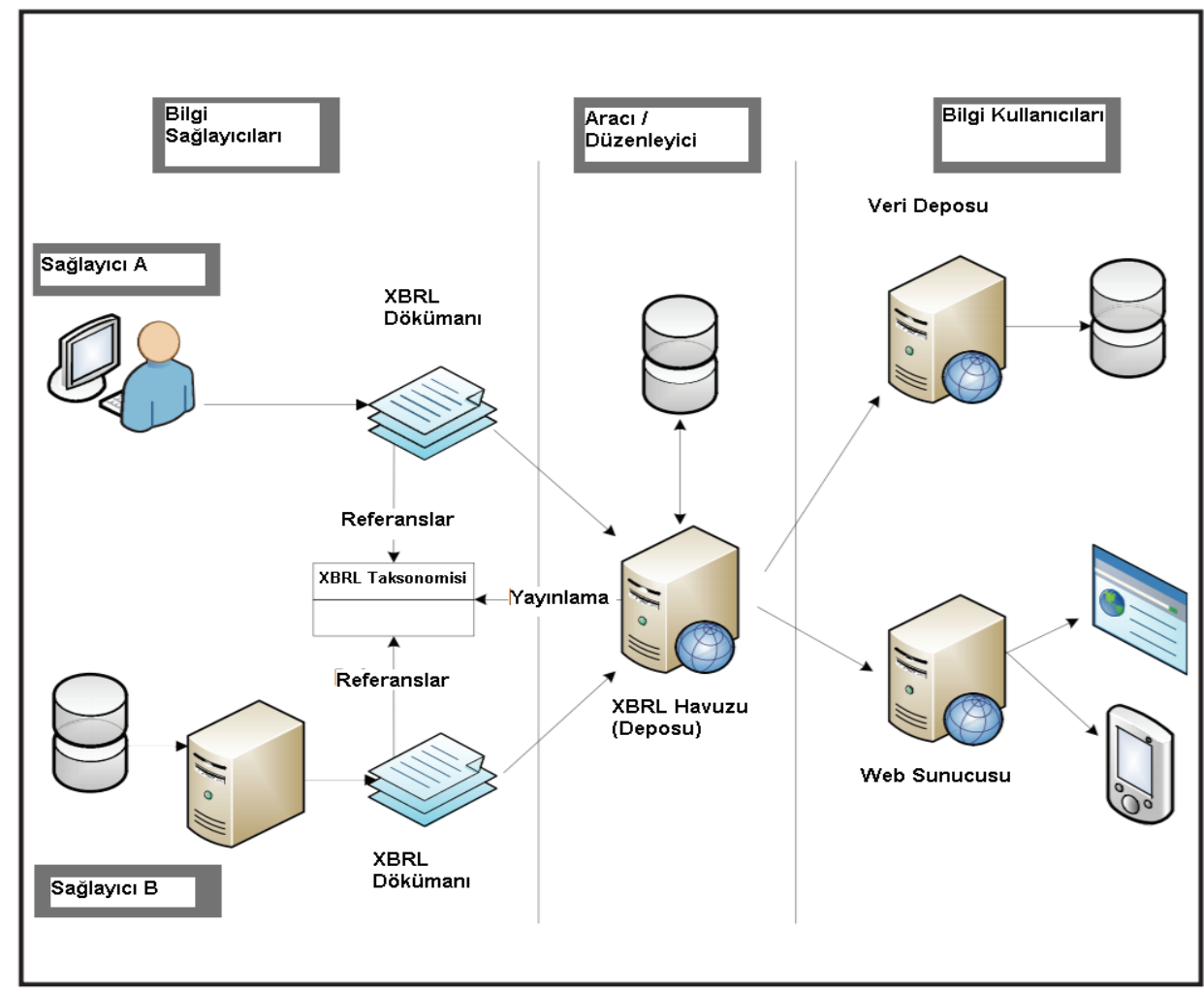

Şekil- 1: Tipik Bilgi Akışı

Kaynak: ISACA ve IFAC, 2011: S.12 
Taksonomiler finansal tablolar ve sürdürülebilirlik raporları için ilgili kuruluşlarca hazırlanmıştır. International Federation of Accountants (IFAC) bünyesindeki International Auditing and Assurance Standards Board (IAASB) 14 Temmuz 2008'de "Strategy and Work Program 20092011" başlıklı çalışma programını yayınlamıştır. Bu çalışmada yer verilen programa göre 2009'un ilk çeyreğinde XBRL çalışmalarına başlanılması planlanan finansal tablolar için taksonomi çalışmaları tamamlanmış ve yayınlanmıştır. 1998 yılında AICPA tarafından başlatılan XBRL çalışmaları sonucunda günümüzde pek çok ülke ve kuruluş XBRL ile kurumsal raporlama yapılması konusunda çalışmalar yapmaktadir. XBRL International'nn resmi internet sitesi olan https://www.xbrl.org/ 'dan alınan bilgiye göre XBRL International'in Belçika, Kanada, Çin, Danimarka, Almanya, Finlandiya, Fransa, İrlanda, İtalya, Japonya, Kore, Lüksemburg, Hollanda, Güney Afrika, İspanya, İsveç, İngiltere, ABD, Meksika, Malezya, Sudi Arabistan, İsrail, Endonezya, Ürdün, Nijerya, Litvanya, Singapur, Avusturya'dan 442 üyesi mevcuttur. 2009 yılında the US SEC halka açı işletmelerin finansal raporları için XBRL'yi zorunlu kılmıştır (https://www.sec.gov). Ülkemizde Kamu Gözetimi, Muhasebe ve Denetim Standartları Kurumu bünyesinde "20 Kasım 2013 tarihi itibariyle XBRL Türkiye Temsilciliği kurulmuştur. Temsilcilik bünyesinde XBRL'nin, Ülkemizdeki raporlama süreçlerinde kullanımına yönelik teknik düzeyde çalışmalar yapılması planlanmaktadır (KGK, 2013).

\section{GRI XBRL Taksonomisi}

Finansal raporlama için XBRL taksonomisi oluşturma, yayınlama ve finansal raporlamada XBRL'nin kullanılabilmesi için yapılan çalışmalar 1998'den beri önemli gelişmeler göstermiştir.

XBRL'nin geniş veri yelpazesine sahip olma yeteneği performans ve sürdürülebilirlik raporlaması için bir dizi temel performans göstergesini (KPI) desteklemektedir. Buna Global Raporlama Girişimi kurallarına göre raporlama da dahildir. Sürdürülebilirlik raporlaması birçok farklı ölçüm tipini içerir. XBRL, dahili, endüstri, global sürdürülebilirlik raporlama taksonomilerinin birbirine bağlı gruplarının oluşturulmasını sağlar (ISACA ve IFAC, 2011: s.15). Diğer bir ifadeyle XBRL sürdürülebilirlik raporlaması için de kolaylıkla uygulanabilir.

122 Muhasebe ve Vergi Uygulamaları Dergisi 
Sürdürülebilirlik raporlarının daha yaygın kullanımı finansal ve sürdürülebilirlik raporlaması amaçları için XBRL'nin daha yaygın bir şekilde kurumsal olarak benimsenmesi ile bağlantılı olabilir (Baumunk, 2009: s.11). XBRL finansal raporlamada kullanılmak amaciyla geliştirilmiş bir biçimlendirme dilidir. Ancak günümüzde sürdürülebilirlik konularına verilen önem ve paydaşların işletmeyle ilgili alacakları kararlarında işletmenin sürdürülebilirlik performanslarını da dikkate almaları XBRL'nin sürdürülebilirlik raporlarının hazırlanmasında da kullanılmasının uygun olacağını göstermektedir.

Sürdürülebilirlik raporlarının XBRL ile hazırlanabilmesi için gerekli çalışmalar 2011 yılından itibaren GRI tarafindan yapılmaya başlanmıştır. Diğer bir ifadeyle, son 6 yılda XBRL ile sürdürülebilirlik raporlaması konusunda çalışmalar yapılmaktadır. Literatürde, Arndt vd. (2006), Isenmann ve Marx-Gomez (2009) ve Mota vd. (2015) tarafindan yapilan çalışmalarda GRI G3 sürdürülebilirlik raporlaması kılavuzu temelinde sürdürülebilirlik raporlarının XBRL ile hazırlanmasını sağlayacak bir yapı önerilmiştir. Faboyede (2011) çalışmasında, Nijerya'da ve gelişen dünyada paydaşların finansal raporlama yanında sürdürülebilirlik raporlaması için de XBRL kullanımına sıcak baktığı, rekabet avantajı elde etmek isteyen işletmelerin işletmelerindeki pilot XBRL projelerinde çabalarını arttırmaları gerektiği, XBRL konusunda farkındalık yaratılması gerektiği, eğitimlerin verilmesi gerektiği görüşlerini dile getirmiştir. Sürdürülebilirlik konularına her geçen gün daha fazla önem verilmesi gerekmesine rağmen, birçok ülkede gönüllülük esasına dayalı olarak düşünüldüğünde sürdürülebilirlik raporlarının hazırlanması ve sunulması, aynı zamanda XBRL ile sürdürülebilirlik raporlarının hazırlanması ve sunulmasının desteklenmesi işletme ve paydaşları açısından faydalı olacaktır.

\subsection{GRI XBRL Taksonomisinin Gelişimi}

Sürdürülebilirlik raporlaması konusunda söz sahibi olan ve sürdürülebilirlik raporlaması kılavuzlarını hazırlayan ve yayınlayan GRI, sürdürülebilirlik raporlaması için XBRL taksonomisi hazırlama çalışmalarına 2011 yılında başlamıştır. https://www.globalreporting.org/information/news-and-press-center/ 'den edinilen bilgiye göre, 24 Haziran 2011 tarihinde GRI ve Deloitte Hollanda işbirliğinde GRI G3 ve G3.1 Kılavuzları için XBRL 
taksonomisi hazırlama konusunda bir toplantı yapılmış ve proje anlaşması imzalanmıştır. "Bu yeni XBRL taksonomisi sürdürülebilirlik verilerini raporlarında etiketleyebilmelerine imkan sağlayacaktır. $\mathrm{Bu}$ taksonomi, işletmelerin sürdürülebilirlik performans verilerinin kalitesini ve bütünlügüün geliştirmesine yardımcı olacaktır. Bu yatırımcıların, denetçilerin ve diğer rapor kullanıcılarının aşırı manuel çalışma yapmaya gerek kalmaksızın GRI verisine daha hızlı ve kolay erişmesini ve bunları karşılaştırabilmesini sağlayacaktır (https://www.globalreporting.org/information/news-and-press-center/ ).

GRI G3 ve G3.1 k1lavuzları için XBRL taksonomisi oluşturma çalışmaları kapsamında GRI ve Deloitte Hollanda işbirliğinde 20 Ekim 2011 tarihinde raporlama yapan kuruluşlar, yazılım şirketleri, standart yapmakla yetkili kuruluşlar, güvence sağlayan kuruluşlar, analistler, bilgi aracıları ve diğer kuruluşların da katıldığı ilk toplantısını gerçekleştirmiştir. Yapılan çalışmalar sonucunda 23 Aralık 2011 tarihinde GRI XBRL Taksonomisi "açıklama taslağı (exposure draft) yayınlanmış, 1 ay boyunca taksonomilerin ve ilgili belgelerin incelenmesi ve gerekirse uygulanması sonucu elde edilecek deneyimlerin paylaşılması için yorum alınmıştır.

Kasım 2013'te GRI G4 Sürdürülebilirlik Raporlaması Kılavuzlarının yayınlanması ile birlikte GRI ve Deloitte Hollanda, GRI XBRL Taksonomisini güncelleyerek “GRI Taksonomisi 2013” ü yayınlamıştır. Yapılan çalışmalar sonrasında ise 2014 yılında "GRI Taksonomisi 2014”ü yayınlamıştır. GRI tarafından GRI Taksonomisinin oluşumunu, alınan kararlarının nedenlerinin açıklanması, taksonomiyi oluşturmada dikkate alınan adlandırma kurallarının açıklanması için 18 Kasım 2014 tarihinde "GRI Taxonomy Architecture \& Style Guide" başliklı rehber yayınlanmıştır.

Dünya Bankası (the World Bank) 2014 y1lı GRI G4 ilkelerine göre hazırladığ1 sürdürülebilirlik raporunda GRI Taksonomisinin son sürümünü kullanmıştır (https://www.globalreporting.org/). https://www.globalreporting.org/services/ göre bununla birlikte, ING Group 2014 Yillik Raporu, Deloitte Netherlands 2014/2015 Sürdürülebilirlik Raporu, 2012/2013 Sürdürülebilirlik Raporu, 2011/2012 Sürdürülebilirlik Raporu, Ernst\&Young Netherlands 2012 Y1llık Raporu, SAP AG 2012 Entegre Raporu, The World Bank 2015 Sürdürülebilirlik Raporu, CLP Holdings Limited 2014 Sürdürülebilirlik 
Raporu, Hong Kong Productivity Council 2012-2013 Sürdürülebilirlik Raporu, GRI XBRL Taksonomisi ile de hazırlanmış raporlardır.

19 Mayıs 2016 tarihinde, uluslararası sürdürülebilirlik standartları belirleyen GRI 5.GRI Global Konferansının ikinci gününde en yeni teknoloji girişimi olan Dijital Raporlama Birliği'ni ilan etmiştir. Dijital Raporlama Birliği, sürdürülebilirlik raporlamasında iki temel zorluğa değinecektir: yapılandırılmış verilerin eksikliği ve dijital raporlama için talep eksikliği. Girişim, bir XBRL taksonomisini ve sayısal raporların hazırlanması için bir platform teşvik ederek dijital raporlama için teknik altyapı oluşturacaktır (https://www.globalreporting.org/information/).

\subsection{GRI XBRL Taksonomisi 2014}

GRI Taksonomisinide, belli bir amaca yönelik tüm kavramlar, tüm standartlar, kılavuz ilkeleri içeren, bu kavramları ve ilkeleri birleştiren giriş noktaları mevcuttur. Bu giriş noktaları, GRI G4 Kılavuzları için giriş noktası, GRI G3.1 Kilavuzları için giriş noktası ve GRI G3 Kılavuzları için giriş noktası olmak üzere 3 grupta açıklanmıştır. Her bir giriş noktası her bir kılavuz için şemalar, etiketler, bağlantı tabanı (linkbase) ve etiketleri içeren XML dosyalarından oluşmaktadır. GRI Taksonomi 2014'te giriş noktaları dişında GRI G3, G3.1 ve G4 Sürdürülebilirlik Raporlaması Kılavuzları için etiketler, kavramlar, boyutsal kavramlar, tanımlar ve sunumlar XML belgesi şeklinde hazırlanmış ve sunulmuştur.

GRI Taksonomisi, boyutsal yapıyı modellemek için sunum bağlantı tabanı (presentation linkbase) ve tanım bağlantı tabanını (definition linkbase) kullanır. Sunum bağlantı tabanı GRI ilkelerinin yapısını yansıtır ve raporlayıcılar tarafindan taksonomide raporlanması gereken ögeyi bulmak için kullanılabilir. Tanım bağlantı tabanı boyutsal yapının teknik tanımlarını içerir ve rapor edilen verilerin geçerliliğini doğrulamak için kullanılabilir (GRI ve Deloitte, 2013: s.9).

Sürdürülebilirlik raporlarını GRI Taksonomisini kullanarak XBRL ile hazırlamak isteyen işletmeler, bu üç giriş noktası ve iki bağlantı tabanındaki modelleri ve taksonomileri kullanabilirler. Seçilen giriş noktasındaki ve bağlantı tabanındaki taksonomiler ile XML dosyası şeklinde sürdürülebilirlik raporu XBRL ile hazırlanmış olur.

$125 \quad$ Muhasebe ve Vergi Uygulamaları Dergisi 
Taksonomiyi oluşturmada dikkate alınan adlandırma kurallarının açıklanması için GRI tarafindan 18 Kasım 2014 tarihinde "GRI Taxonomy Architecture \& Style Guide" başlıklı rehber yayınlanmıştır. GRI XBRL Taksonomisi'ne https://www.globalreporting.org/services/ adresinden ulaşılabilir. GRI Taksonomisi Uygulama Rehberinde GRI G4 Sürdürülebilirlik Raporlaması İlkeleri Özel Standart Bildirimler kapsamında olan G4-EN3-Kuruluş içindeki enerji tüketimi ilkesinin XBRL'de nasıl modelleneceği şu şekilde örneklendirilmiştir:

\author{
XBRL Modelleme \\ EnergyConsumptionTable \\ EnergyTypeAxis \\ EnergyTypeDomain \\ ElectricityMember \\ HeatingMember \\ CoolingMember \\ SteamMember \\ EnergyConsumptionLineItems \\ EnergyConsumption
}

Kaynak: GRI ve Deloitte, 2013: s.9-10

\title{
5. SONUÇ
}

İşletme faaliyetleri sonucunda tüm paydaşlar için finansal etkiler yaratırken, finansal olmayan etkiler de yaratmaktadır. Finansal olmayan etkiler kapsamında işletme faaliyetleri ile ekonomi, çevre ve toplum üzerinde yaratılan etkiler kastedilmektedir. İşletme amaçlarına ulaşmak için faaliyetleri ile ekonomi, çevre ve toplum üzerindeki olumsuz etkilerini azaltması, olumlu etkiler yaratması gerekmektedir. Ayrıca bu etkilerin sürdürülebilirlik raporları ile bilgi kullanıcılarına aktarılması, zorunluluk getiren bir yasal düzenleme olmasa bile gönüllülük esasına dayalı olarak gerçekleştirilmektedir.

$126 \quad$ Muhasebe ve Vergi Uygulamaları Dergisi 
Sürdürülebilirlik raporları, işletmeler tarafından gönüllülük esasına dayalı olarak hazırlanan ve sunulan raporlardır. Sürdürülebilirlik raporu işletme faaliyetlerinin ekonomik, çevresel ve sosyal etkilerinin paydaşlara aktarılmasında kullanılan rapordur. Sürdürülebilirlik raporunun hazırlanması ve sunulmasında GRI tarafindan hazırlanan ve yayınlanan sürdürülebilirlik raporlaması kılavuzlarında açıklanan ilkeler esas alınmaktadır. İşletmelerin, 31 Aralık 2015 tarihinden sonra başlayan dönemden itibaren GRI G4 Sürdürülebilirlik Raporlaması Kılavuzlarında açıklanan ilkeler esas alınarak sürdürülebilirlik raporlarını hazırlamaları önerilmektedir.

Sürdürülebilirlik raporları dünya çapında her geçen gün artan bir öneme sahiptir. http://database.globalreporting.org/ adresinde kullanıma sunulan GRI Database'de 22 Ağustos 2017 tarihi itibariyle 11.087 işletme tarafindan yayınlanmış olan 28.102 tanesi GRI Sürdürülebilirlik Raporlaması Kılavuzlarına uygun olarak hazırlanmış olan 43.128 adet rapor mevcuttur. GRI ilkelerine uygun olan bu raporlar PDF formatında hazırlanıp GRI Database'ye eklenmiş, bilgi kullanıcılarına sunulmuştur. Ancak, bilişim teknolojileri ve internetin gelişmesi gibi teknolojik gelişmeler sürdürülebilirlik raporlarının da XBRL ile hazırlanması ve yayınlanması konusunu gündeme getirmiştir.

XBRL, işletmenin finansal ve finansal olmayan performansının varolan raporlama standartları ve ilkelerine göre hazırlanmış spefikasyonlar, taksonomiler kullanılarak internet ortamında raporlanmasını sağlayan, bilgi kullanıcılarının bu raporlar üzerinde değişiklik ve analiz yapmasına imkan veren raporlama dilidir. XBRL'nin finansal raporlamada kullanımı için AICPA tarafından 1988 yılında çalışmalara başlanmıştır. Sürdürülebilirlik raporlarının XBRL ile hazırlanması için ise GRI ve Deloitte Hollanda öncülüğünde 2011 yılından beri çalışmalar yapılmaktadır. Yapılan çalışmalar sonrasında GRI Taksonomileri hazırlanmış ve yayınlanmış olup, güncel sürdürülebilirlik raporlaması taksonomisi GRI Taksonomisi 2014'tür.

Başta Dünya Bankası, Deloitte, ING, Ernest\&Young olmak üzere pek çok kuruluş XBRL ile sürdürülebilirlik raporlarının hazırlanması ve yayınlanmasını desteklemektedir. Teknolojik gelişmelerin hızı ve hayatımızın her alanına girdiği düşünüldügüunde, sürdürülebilirlik raporlarının hazırlanması ve sunulmasında XBRL kullanımının tüm paydaşlar tarafından yapılacak olan hazırlık, analiz ve denetim faaliyetlerini kolaylaştırabileceği söylenebilir.

$127 \quad$ Muhasebe ve Vergi Uygulamalarl Dergisi 


\section{KAYNAKÇA}

Acar, V. Öksüz, Ö. (2013). Finansal Bilgilerin Elektronik Ortamda Paylaşımı ve E-Defter Uygulamaları. Akademik Araştırmalar ve Çalışmalar Dergisi / Journal of Academic Researches and Studies Y1l 5 Say1 8 - Mayıs 2013 / Volume 5 - Number 8 - May 2013

Arndt, H-K. Isenmann, R. Browowski, J. Thiessen, I. Marx-Gomez, J. (2006). Sustainability Reporting Using the eXtensible Business Reporting Language (XBRL). https://pdfs.semanticscholar.org/74b0/5bc530ee4403abd7af9da79a32dcc ccda9f2.pdf (04.03.2018)

Baumunk, J. (2009). Sustainability Reporting and XBRL. https://papers.ssrn.com/sol3/papers.cfm?abstract_id=1620567 (04.03.2018)

Bayazıtl1, E. (2002). Sürekli Denetim: Geleceğin Denetimi. Muhasebe ve Denetime Bakış. Sayı 6. Şubat 2002

Beerbaum, Dirk. (2015). Towards an XBRL-Enabled Corporate Governance Reporting Taxonomy An Empirical Study of NYSE-Listed Financial Institutions. University of Surrey, Faculty of Business, Economic and Law Surrey Business School, July 2015

Coşkun, M.B. (2011). Genişletilebilir İşletme Raporlama Dili'nin (XBRL) Muhasebe - Denetim faaliyetlerinde Kullanılmasl ve Örnek Uygulama. Yayınlanmamış Yüksek Lisans Tezi. T.C. Hitit Üniversitesi SBE İşletme ABD.

Faboyede, O.S. (2011). Environmental protection and Sustainability Reporting: Extensible Business Reporting Language (XBRL) Interative Data to the Rescue. Journal of Sustainable Development and Environmental Protection. Vol.1 No.2.

Francis, P. (2012). Intro to XBRL accountants today.

GRI, Deloitte. (2011). GRI Taxonomy Implementation Guide. https://www.globalreporting.org/resourcelibrary/GRI-Taxonomy-2013Implementation-Guide.pdf (21.07.2017)

GRI-Global Reporting Initiative. (2000). G3 Sürdürülebilirlik Raporlaması İlkeleri.

$128 \quad$ Muhasebe ve Vergi Uygulamaları Dergisi 
GRI-Global Reporting Initiative. (2013). G4 Sürdürülebilirlik Raporlaması Kılavuzları, Raporlama İlkeleri ve Standart Bildirimler.

http://www.aicpa.org/interestareas/frc/accountingfinancialreporting/xbrl/ pages/howxbrlworks.aspx (22.08.2017)

http://www.un-documents.net/ocf-a2.htm\#I (14.08.2017)

https://wmaraci.com/nedir/stylesheet (04.03.2018)

https://www.globalreporting.org/information/news-and-presscenter/Pages/New-XBRL-taxonomy-to-make-sustainability-reportsmore-useful-to-investors-.aspx (21.08.2017)

https://www.globalreporting.org/information/news-and-presscenter/Pages/XBRL-PROVIDES-HIGH-LEVEL-OVERVIEW-FORWORLD-BANK.aspx (14.08.2017)

https://www.globalreporting.org/information/news-and-presscenter/Pages/GRI-launches-Digital-Reporting-Alliance.aspx (14.08.2017)

https://www.globalreporting.org/information/sustainabilityreporting/Pages/default.aspx (14.08.2017)

https://www.globalreporting.org/services/Analysis/XBRL_Reports/Pages /default.aspx (22.08.2017)

https://www.globalreporting.org/services/Analysis/XBRL_Reports/Pages /default.aspx'na

https://www.iaasb.org/projects/xbrl (22.08.2017)

https://www.ifac.org/news-events/2008-07/ifacs-international-auditingand-assurance-standards-board-issues-strategy-and-w (22.08.2017)

https://www.sec.gov (16.08.2017)

https://www.sec.gov/page/osd-homepage (16.08.2017)

https://www.xbrl.org/ (16.08.2017)

https://www.xbrl.org/the-standard/what/an-introduction-to-xbrl/ (16.08.2017)

ISACA IFAC. (2011). Leveraging XBRL for Value in Organizations. https://www.ifac.org/publications-resources/leveraging-xbrl-valueorganizations (21.08.2017)

129 Muhasebe ve Vergi Uygulamaları Dergisi 
Isenmann, R. Marx-Gomez, J. (2009). Advanced corporate sustainability reporting - XBRL taxonomy for sustainability reports based on the G3guidelines of the Global Reporting Initiative. European conference of the Czech Presidency of the Council of the EU Towards Eenvironment Opportunities of SEIS and SISE: Integrating Environmental Knowledge in Europe. http:/www.e-envi2009.org/proceedings/

Karasioğlu, F. Eryiğit, O. (2005). Finansal Raporlama ve XBRL (Genişletilebilir Kurumsal Raporlama Dili). Süleyman Demirel Üniversitesi İktisadi ve İdari Bilimler Fakültesi Dergisi. C.10, S2 s.133152

Kernan, K. (2009). The Story of Our New Language. https://www.aicpa.org/InterestAreas/FRC/AccountingFinancialReporting /XBRL/DownloadableDocuments/XBRL_09_web_final.pdf (21.08.2017)

KGK. Kamu Gözetimi Muhasebe ve Denetim Standartları Kurumu. (2013). XBRL Türkiye Temsilciliği, Kamu Gözetimi, muhasebe ve Denetim Standartları Kurumu Bünyesinde Oluşturuldu. 26 Eylül 2013 tarih 2013/3 say1lı Basın Duyurusu

Moore, D. (2002). Audit \& Control Implications of XBRL. The Canadian Institute of Chartered Accountants. http://www.youscribe.com/BookReader/Index/525178?documentId=496 $301(16.08 .2017)$

Mota, E. Costa, D. Caetano da Silva, P. (2015). Sustainability Reports Based on XBRL through a Service-Oriented Architecture Approach. International Conference on Circuits and Systems (CAS 2015).

Roohani, S. (2013). Integrated Reporting, XBRL, and Corporate Governance. $\quad$ http://eycarat.faculty.ku.edu/myssi/XBRL2013/4Saeed\%20Roohani-

Integrated\%20Reporting, \%20XBRL,\%20and\%20Corporate\%20Governa nce.pdf

Sevim, A. Temizel, F. (2009). Geleceğin Finansal Bilgi Paylaşım Platformu: XBRL (Extensible Business Reporting Language Genişletilebilir İşletme Raporlama Dili). http://sead.selcuk.edu.tr/sead/article/viewFile/221/217 (16.08.2017)

$130 \quad$ Muhasebe ve Vergi Uygulamalarl Dergisi 
Tokel, Ö.E. Yücel, E.M. \& Öksüz, B. (2007). Türkiye'de XBRL'ye Geçiş Sürecinin Yol Haritası. Active Dergisi.

UN World Commission on Environment and Development(WCED). (1987). Report of the World Commission on Environment and Development: Our Common Future. Brundtland Raporu. http://www.undocuments.net/our-common-future.pdf , (8.4.2015)

Uyar, S. Çelik, M. (2006). Sürekli Kamuyu Aydınlatma Ve İnternet Ortamında Finansal Raporlama Sürecinde Kullanılan Diller. http://www.onlinedergi.com/makaledosyalari/51/pdf2006_2_9.pdf (14.08.2017)

www.uncsd2012.org/history.html\#sthash.5vJIB5mW.dpuf (16.08.2017)

131 Muhasebe ve Vergi Uygulamaları Dergisi 